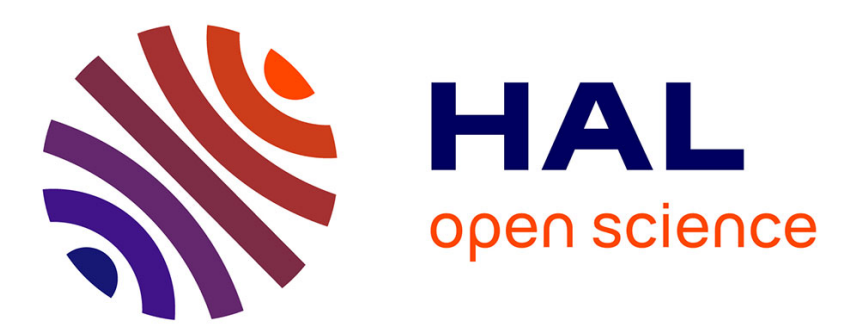

\title{
A fuzzy-logic-based controller for methane production in anaerobic fixed-film reactors
}

\author{
Angel Robles Martinez, Eric Latrille, M.V. Ruano, Jean-Philippe Steyer
}

\section{To cite this version:}

Angel Robles Martinez, Eric Latrille, M.V. Ruano, Jean-Philippe Steyer. A fuzzy-logic-based controller for methane production in anaerobic fixed-film reactors. Environmental Technology, 2017, 38 (1), pp.42-52. 10.1080/09593330.2016.1184321 . hal-01605963

\section{HAL Id: hal-01605963 https://hal.science/hal-01605963}

Submitted on 25 May 2020

HAL is a multi-disciplinary open access archive for the deposit and dissemination of scientific research documents, whether they are published or not. The documents may come from teaching and research institutions in France or abroad, or from public or private research centers.
L'archive ouverte pluridisciplinaire HAL, est destinée au dépôt et à la diffusion de documents scientifiques de niveau recherche, publiés ou non, émanant des établissements d'enseignement et de recherche français ou étrangers, des laboratoires publics ou privés. 


\title{
A fuzzy-logic-based controller for methane production in anaerobic fixed-film reactors
}

\author{
A. Robles, E. Latrille, M.V. Ruano \& J.P. Steyer
}

To cite this article: A. Robles, E. Latrille, M.V. Ruano \& J.P. Steyer (2016): A fuzzy-logic-based controller for methane production in anaerobic fixed-film reactors, Environmental Technology, DOI: $10.1080 / 09593330.2016 .1184321$

To link to this article: http://dx.doi.org/10.1080/09593330.2016.1184321

Accepted author version posted online: 29

Apr 2016.

Submit your article to this journal $\sqsubset$

a)

View related articles ¿

View Crossmark data \lceil 
Publisher: Taylor \& Francis \& Informa UK Limited, trading as Taylor \& Francis Group

Journal: Environmental Technology

DOI: $10.1080 / 09593330.2016 .1184321$

\title{
A fuzzy-logic-based controller for methane production in anaerobic fixed-film reactors
}

\author{
A. Robles ${ }^{\mathrm{a}, \mathrm{b}, *}$, E. Latrille ${ }^{\mathrm{b}}$, M.V. Ruano ${ }^{\mathrm{c}}$ and J.P. Steyer ${ }^{\mathrm{b}}$ \\ a Institut Universitari d'Investigació d’Enginyeria de l'Aigua i Medi Ambient, IIAMA, Universitat Politècnica \\ de València, Camí de Vera s/n, 46022 Valencia, Spain (e-mail: ngerobma@upv.es) \\ c INRA, UR0050, Laboratoire de Biotechnologie de l’Environnement, Avenue des Etangs, F-11100, \\ Narbonne, France (e-mail: eric.latrille@supagro.inra.fr; jean-philippe.steyer@supagro.inra.fr) \\ c Departament d’Enginyeria Química, Escola Tècnica Superior d’Enginyeria, Universitat de València, \\ Avinguda de la Universitat s/n, 46100 Burjassot, Valencia, Spain (e-mail: m.victoria.ruano@uv.es) \\ * Corresponding author: tel. +34 9638799 61, fax +34 9638790 09, e-mail: ngerobma@upv.es
}

\begin{abstract}
The main objective of this work was to develop a controller for biogas production in continuous anaerobic fixed-bed reactors, which used effluent total volatile fatty acids (VFA) concentration as control input in order to preyent process acidification at closed-loop. To this aim, a fuzzy-logicbased control system was developed, tuned and validated in an anaerobic fixed-bed reactor at pilot scale that treated industrial winery wastewater. The proposed controller varied the flow-rate of wastewater entering the system as a function of the gaseous outflow rate of methane and VFA concentration. Simulation results show that the proposed controller is capable to achieve great process stability even when operating at high VFA concentrations. Pilot results showed the potential of this control approach to maintain the process working properly under similar conditions to the ones expected at full-scale plants.
\end{abstract}

\section{Keywords}

Anaerobic fixed-bed reactor; fuzzy-logic control; methane; pilot scale; winery wastewater.

\section{Introduction}


One of the key issues for global sustainable development is lowering the consumption of fossil fuels, which represents up to $80 \%$ of the global energy consumption [1]. Hence, one big challenge of this century is to develop new competitive sources of renewable energy, capable of replacing fossil fuels with a minimum impact for both environment and society [2]. In this respect, alternative energy sources such as methane from biogas produced in anaerobic digestion (AD) of waste must be considered.

Methane has been widely applied to several energetic applications, such as gas turbines and vapour generation, including the direct injection to the natural gas distribution system. Moreover, methane obtained by $\mathrm{AD}$ can be considered a carbon neutral energy source because of the net balance of greenhouse gases emissions.

Nowadays, a great deal of effort has been put into the study of high-rate systems that use self-immobilised biomass (e.g. up-flow anaerobic sludge blanket (UASB), expanded granular sludge blanket (EGSB) or fixedbed bioreactors) (see, for instance [3-5]. Due to the considerable number of factors affecting the anaerobic degradation of biomass and the high complexity and instability of AD processes [6], the optimisation of this kind of systems is a big challenge to maximise methane production. Thus, the development of advanced monitoring and control systems may allow successful implementation, stabilisation and optimisation of these high-rate AD systems.

Concerning monitoring equipment, biogas composition and flow rate are commonly used as indicators for monitoring the performance of $\mathrm{AD}$ processes. These indicators can be, however, insufficient to evaluate the process performance, since they may not reflect disturbances in the process leading to situations where quick recovery is not possible anymore. In this respect, volatile fatty acid (VFA) concentration has been suggested to be an adequate state indicator for monitoring the performance of $\mathrm{AD}$ processes because of different factors, such as: i) it is the main pre-methanogenic intermediate, ii) allows indicating process imbalance, and iii) could be useful for obtaining specific information for process diagnosis[7]; and iv) it gives fast and reliable information of process status compared to other common indicators such as $\mathrm{pH}$, alkalinity, gas production, and gas composition [8] 
With regard to control strategies, since classical PID controllers are mainly limited to single-input-singleoutput control loops and to linear processes, different advanced control approaches have been theoretically analysed and experimentally validated in order to control AD processes. Fuzzy-logic control, for instance, permit dealing with uncertainties and does not require a large amount of data and/or a rigorous mathematical model, whilst allows developing multiple-input-multiple-output control schemes. An important advantage of fuzzy control is that nonlinear and linear systems are equally treated. To account for the nonlinearity in the system, membership functions can be customised to bring the system to a more linear behaviour. PID controllers have some difficulties in tuning for the whole range of working points. Mostly tuning procedure is done for a specific working point. When the working point changes their performance deteriorates and the errors at the output signal or the controlled variable tend to increase. Problems with tuning the PID controllers increase when the system to be controlled has non-linear dynamics. Fuzzy control is an interesting alternative, especially in the systems, which have non-linear characteristics. The theory of fuzzy sets was introduced by Zadeh [9] in 1965 and constituted an easy tool for representing heuristic knowledge using linguistic labels implemented in linguistic rules. It mainly consists in a fuzzy inference process that involves membership functions, fuzzy logic operators and knowledge rules. The membership functions constitute the representation of a degree of membership (degree of truth) to a fuzzy set that is associated to a linguistic label of a linguistic variable for a given input numerical value. The rules IF-THEN allow formulating the expert knowledge in a computable way by means of different operators such as AND or OR. Fuzzy-logic control has been widely implemented in wastewater treatment over the last decades and has been successfully applied in several AD processes long time ago (see, for instance, [10-17]). Hence, fuzzy logic is a powerful tool for AD control since it is capable of optimising different kinds of processes under dynamic operating and loading conditions by means of applying valuable expert knowledge $[18,19]$.

The objective of this study was to develop a control system for methane production in a continuous fixed-bed anaerobic reactor at pilot scale, which used VFA concentration as control input in order to prevent process acidification at closed-loop. Thus, besides the gaseous outflow rate of methane, the controller included the VFA concentration as state indicator for process performance. The novelty of this work not only lies on the 
incorporation of the VFA concentration as input variable of the controller, but also on its validation under similar conditions to the ones expected at full-scale plants. Moreover, the VFA input variable allowed defining boundary conditions for the performance of the proposed multiple-input controller.

\section{Materials and methods}

\subsection{Pilot plant description and operation}

Figure 1 shows the flow diagram and the instrumentation of the continuous anaerobic fixed-bed reactor used in this study. This plant had a total volume of $0.36 \mathrm{~m}^{3}$. The support media was cloisonyl $\left(180 \mathrm{~m}^{2} \cdot \mathrm{m}^{-3}\right.$ specific surface). The anaerobic reactor was jacketed and connected to a water heating system for temperature control. Moreover, the plant was equipped with a lower-layer $\mathrm{pH}$ control by feeding $\mathrm{NaOH}(30 \%)$ to the system.

The plant was fed with raw winery wastewater (WWW) from local cellars located in the area of Narbonne, France. The wastewater was stored in a feed tank $\left(27 \mathrm{~m}^{3}\right)$ that was connected to a dilution system of $0.2 \mathrm{~m}^{3}$. Wastewater composition entering the plant was kept nearby stable during the studied period. Hence, the organic loading rate (OLR) varied according with the variations applied in the hydraulic retention time (HRT) (i.e. modifying the influent flow rate). The average influent concentrations to the plant during the studied period were $12.0 \pm 1.0 \mathrm{~g} \cdot \mathrm{L}^{-1}$ of COD and $2.8 \pm 0.8 \mathrm{~g} \mathrm{COD} \cdot \mathrm{L}^{-1}$ of total VFA. Acetate, propionate and butyrate concentrations were $1.7 \pm 0.3,0.8 \pm 0.3$ and $0.2 \pm 0.1 \mathrm{~g} C O D \cdot \mathrm{L}^{-1}$, respectively. The influent flow rate was controlled on-line by the corresponding lower-layer controller. In the reactor, a portion of the liquid was recycled from the bottom to the top for both improving the mixing conditions and favouring the stripping of the produced gases from the liquid phase. The recycling flow rate was controlled in-situ and offline by modifying the opening degree of a manual valve. The fresh substrate was fed through the recycling tubing, thus it was mixed with the recycled liquid and then introduced at the top of the reactor. The buffer solution $(\mathrm{NaOH})$ was also introduced to the reactor through the recycling tubing. The effluent was obtained by gravity as shown in Figure 1 (the reactor operated at constant volume). The generated biogas was measured and analysed on-line before discharging. 
The plant was operated at a controlled temperature of $35^{\circ} \mathrm{C}$. The $\mathrm{pH}$ set point was set to 7.2 . The recycling flow rate during the experimental period was set to $550 \mathrm{~L} \cdot \mathrm{h}^{-1}$. The HRT varied according to the control action.

\subsection{On-line monitoring}

The plant was fully automated and instrumented. The on-line equipment consisted of: one $\mathrm{pH}$ transmitter and one conductivity-temperature transmitter located in the recycling pipe; one temperature transmitter in the anaerobic reactor; one gas pressure transmitter in the head-space of the anaerobic reactor; two flow-rate transmitters (one for the recycling pump and one for the feed pump); one gas flow-rate transmitter (electromagnetic floater-based sensor) and one on-line $\mathrm{CH}_{4} / \mathrm{CO}_{2}$ sensor (Ultramat 22P Siemens), both located in the biogas discharge pipeline; and one on-line titrimetric sensor (Anaerobic Control Analyser AnaSense $^{\circledR}$, AppliTek S.L.) for the measurement of total VFA and alkalinity. The plant also included different lower-layer control loops, which consisted of a classical PID controller for the influent flow rate and two on-off controllers for temperature and $\mathrm{pH}$. The on-line sensors and the automatic equipment were connected to a network system that included several transmitters, an input/output device, and a PC that was in charge of the data acquisition and allowed performing multi-parameter control. The input/output device was managed by software developed at INRA-LBE. The main aim of this software was to carry out data logging, advanced control actions calculations and process supervision by using Matlab ${ }^{\circledR}$ routines.

\subsection{Sampling and off-line measurements}

Besides the on-line process monitoring, grab samples of the influent and the effluent were collected once a day. From both influent and effluent, COD was determined once a week, whilst the composition of VFAs, i.e., acetate (C2), propionate (C3), iso-butyrate and butyrate (iC4 and C4), and iso-valerate and valerate (iC5 and C5), was analysed once a day. COD was determined by the spectrophotometric micro-method (Tube Test MR, AQUALYTIC ${ }^{\circledR}$ ), according to Standard Methods [20]. The composition of total VFAs was determined by liquid chromatography (Perkin Elmer ${ }^{\circledR}$, Clarus 580 LC). $0.5 \mathrm{~mL}$ of sample was introduced into a vial with the same amount of etalon $(1 \mathrm{~g}$ of ethyl-2-butiric acid in $1 \mathrm{~L}$ of distilled water, acidified to $5 \%(\mathrm{v} / \mathrm{v})$ with $\left.\mathrm{H}_{3} \mathrm{PO}_{4}\right)$, which was used as standard. Moreover, a control solution containing the VFAs to be 
determined $\left(1.078 \mathrm{~g} \mathrm{C} 2 \cdot \mathrm{L}^{-1} ; 1.022 \mathrm{~g} \mathrm{C} 3 \cdot \mathrm{L}^{-1} ; 1.068 \mathrm{~g} \mathrm{iC} 4 \cdot \mathrm{L}^{-1} ; 1.111 \mathrm{~g} \mathrm{C} 4 \cdot \mathrm{L}^{-1} ; 1.079 \mathrm{~g} \mathrm{iC} \cdot \mathrm{L}^{-1}\right.$; and 1.151 $\mathrm{g} \cdot \mathrm{C} 5 \mathrm{~L}^{-1}$ ) was also analysed.

\subsection{Control system description}

The proposed fuzzy-logic controller consisted of a multiple-input-single-output control structure where the control variable was the gaseous outflow rate of methane, and the manipulated variable is the influent flow rate. Besides the gaseous outflow rate of methane, the controller included VFA concentration as control input in order to prevent, for instance, process acidification at closed-loop. Therefore, the controller used the VFA concentration as state indicator of the process performance.

The gaseous outflow rate of methane was calculated by means of the methane concentration in the gas phase and the measured biogas flow rate. The methane flow rate included composition correction to account for the dependence of volumetric flow rate on biogas density. Thus, taking into account the on-line information from the biogas composition $\left(\% \mathrm{CH}_{4}\right.$ and $\left.\% \mathrm{CO}_{2}\right)$ and the measured biogas flow rate ( $\left.G_{M E A S U R E D}\right)$, the methane flow rate $\left(q_{\mathrm{CH}}\right)$ was calculated by Equation 1 .

$$
q_{C H 4}=G_{\text {CORRECTED }} \cdot \% \mathrm{CH}_{4} / 100
$$

where:

$$
\begin{aligned}
& r_{\text {CORRECTED }}=G_{\text {MEASURED }} \cdot \text { frho } \\
& r h O_{\mathrm{CO}_{2}}: \text { volumetric mass of } \mathrm{CH}_{4}\left(0.7168 \mathrm{~kg} \cdot \mathrm{m}^{-3}\right) \\
& r h O_{\mathrm{N}_{2}}: \text { volumetric mass of } \mathrm{CO}_{2}\left(1.9768 \mathrm{~kg} \cdot \mathrm{m}^{-3}\right)
\end{aligned}
$$


Figure 2 shows a block diagram of the proposed fuzzy-logic controller. The controller determined the variation in the influent flow-rate set-point ( $\left.\Delta q_{I N \_S P}\right)$ to be applied to the corresponding PID controller on the basis of three inputs: the error in the methane flow rate ( $e q_{\mathrm{CH}_{4}}$, see Eq. 4$)$, the error difference in the methane flow rate $\left(\Delta e q_{\mathrm{CH}_{4}}\right.$, see Eq. 5), and the error in the effluent VFA concentration ( $\mathrm{eVFA}$, see Eq. 6). A 0.5h-moving average value for $q_{\mathrm{CH}_{4}}\left(q_{\mathrm{CH}_{4}}{ }^{*}\right)$ was considered for reducing possible problems regarding measurement noise. For the effluent VFA concentration, a 2h-moving average value (VFA*) was considered due to the sampling time of the on-line titrimetric sensor. Both moving average values were also selected on the basis of AD process dynamics through experimental observations.

$$
e q_{\mathrm{CH}_{4}}(t)=q_{\mathrm{CH}_{4}}(t)-q_{\mathrm{CH}_{4}-S P}(t)
$$

where:

- $\quad e q_{\mathrm{CH}_{4}}(t)$ : error in the methane flow rate at a given time

- $\quad q_{\mathrm{CH}_{4}}(t)$ : measured methane flow rate at a given time

- $\quad q_{\mathrm{CH}_{4} \mathrm{SP}}(t)$ : methane flow rate set point at a given time

$$
\Delta e q_{\mathrm{CH}_{4}}(t)=\left|e q_{\mathrm{CH}_{4}}(t)\right|-\delta \cdot\left|e q_{\mathrm{CH}_{4}}(t-1)\right|
$$

where:

$\Delta e q_{\mathrm{CH}_{4}}(t)$ : error difference for the methane flow rate at a given time

$\left|e q_{\mathrm{CH}_{4}}(t)\right|:$ absolute value of the error in the methane flow rate at a given time

$\delta$ : modifying algebraic factor (Equation 7)

$\left|e q_{\mathrm{CH}_{4}}(t-1)\right|:$ absolute value of the error in the methane flow rate at the previous control action 


$$
\operatorname{eVFA}(t)=\operatorname{VFA}(t)-V F A_{S P}(t)
$$

where:

$$
\begin{aligned}
& \text { - } \quad \text { VVFA }(t): \text { error in the effluent VFA concentration at a given time } \\
& \text { - } \quad V F A(t): \text { measured effluent VFA concentration at a given time } \\
& \text { - } \quad V F A_{S P}(t): \text { effluent VFA concentration set point at a given time }
\end{aligned}
$$

$\Delta e q_{\mathrm{CH}_{4}}$ is negative or positive depending on whether or not $e q_{\mathrm{CH}_{4}}$ tends to zero, because this equation features a modifying algebraic factor $(\delta)$, which is defined in Eq. 7.

$$
\delta=\frac{e q_{\mathrm{CH}_{4}}(t) \cdot e q_{\mathrm{CH}_{4}}(t-1)}{\left|e q_{\mathrm{CH}_{4}}(t) \cdot e q_{\mathrm{CH}_{4}}(t-1)\right|}
$$

The fuzzy-logic controller was defined following the Takagi-Sugeno structure. As regards the fuzzification stage, three Gaussian membership functions were considered for $e q_{\mathrm{CH}_{4}}$ and $\Delta e q_{\mathrm{CH}_{4}}$ : Negative $(N)$, Zero $(Z)$ and Positive $(P)$; and two Gaussian membership functions were defined for eVFA: High Negative $(N)$ and High Positive $(P)$. As each Gaussian membership function is defined by two parameters (centre, c, and amplitude, a), the control system had a total of 8 parameters as regards the fuzzification stage. Concerning the defuzzification stage, four singleton membership functions were defined for $\Delta q_{I N}$ : High Negative $(H N)$, Low Negative $(L N)$, Low Positive $(L P)$ and High Positive (HP). Therefore, the control system had a total of 4 parameters regarding the defuzzification stage. Including the response time of the control system, a total number of 13 parameters were adjusted. These parameters were iteratively calibrated by selecting the best combination of values (trial-error approach) which resulted in proper control system performances under different perturbations (e.g. methane flow-rate set-point modifications). 
Table 1 shows the resulting grade of membership to the different output linguistic labels that defined the output fuzzy set. The effect of the third right-side term of the rules in Table 1 (i.e., 1 - $\left.\mu(e V F A)_{X}\right)$ is null when the effluent VFA concentration is equal to VFASP (i.e., IF $e V F A=0$ THEN $\mu(e V F A)_{X}=0$ AND $(1-\mu$ $\left.\left.(e V F A)_{X}\right)=1\right)$. On the contrary, the effect of the third right-side term of the rules cancels the corresponding control action when both the effluent VFA concentration is far away from $V F A_{S P}$ (i.e. the absolute value of $e V F A$ tends to 1 ) and the resulting control action tends to increase $e V F A$ in absolute terms (e.g., IF $|e V F A|=$ 1 THEN $\mu(e V F A)_{X}=1$ AND $\left.\left(1-\mu(e V F A)_{X}\right)=0\right)$. It is important to note that the aim of $e V F A$ is to activate the upper and lower boundaries for the controller performance when necessary, not to control the effluent VFA concentration around a given set point $\left(V F A_{S P}\right)$. VFA $A_{S P}$ actually refers to an equilibrium state, far away from which the controller meet boundary operating conditions. In this respect, the controller will not be capable of increasing the influent flow rate when operating around the upper bound value established for VFA (i.e. when $\mu(e V F A)_{P}=1$, see rules \#1, \#2, \#5a and \#6a in Table 1), and it will not be capable of decreasing the influent flow rate when operating around the lower bound value set to VFA (i.e. when $\mu(e V F A)_{N}=1$, see rules \#3, \#4, \#5b and \#6b in Table 1$)$

The output linguistic variable $\left(\Delta q_{I N \_S P}\right)$ was obtained by applying Larsen’s fuzzy inference method [21] using the Max-Prod operator. In the defuzzification stage, the Height Defuzzifier method [22] was employed to obtain a single output value from the output fuzzy set.

In order to avoid possible operating problems not detected by the controller (e.g. emptying of the reactor, overload or washout of microorganisms), the influent flow-rate set point was modified only in a defined range (Eq. 8).

$$
Q_{\min } \leq q_{I N_{-} S P} \leq Q_{\max }
$$

where:

$Q_{\min }: 1 \mathrm{~L} \cdot \mathrm{h}^{-1}$, minimum influent flow rate

- $\quad Q_{\max }: 10 \mathrm{~L} \cdot \mathrm{h}^{-1}$, maximum influent flow rate 
The proposed controller was firstly designed, tuned and simulated using the Fuzzy Logic Toolbox ${ }^{\mathrm{TM}}$ included in the simulation software Matlab ${ }^{\circledR}$ Simulink $^{\circledR}$. To this aim, the mathematical model BNRM2 [23] was used. This model considers key physical, chemical and biological processes taking place in a WWTP. As regards anaerobic digestion, the model considers acidogenesis, acetogenesis and acetoclastic and hydrogenotrophic methanogenesis. Gas-liquid transfer is included through stripping of nitrogen, ammonia, oxygen, hydrogen, methane and carbon dioxide. Moreover, this model includes a chemical model to calculate the $\mathrm{pH}$ and the concentration of inorganic soluble components under its different species, which are involve in different physical, chemical and biological processes (e.g. gas-liquid transfer).

Only the processes involved in anaerobic digestion units were considered in this study for designing the controller. Therefore, it was possible to simulate total VFA concentration and methane production by solving a reduced set of algebraic and differential equations.

Different set points for the gaseous outflow rate of methane were tested (from about 10 to $30 \mathrm{~L}_{\mathrm{CH}}{ }^{\cdot} \mathrm{h}^{-1}$ ). The selected set points for the gaseous outflow rate of methane covered the range of operation of the pilot plant used in this study. Then, the developed controller was validated in the above-mentioned pilot-scale anaerobic fixed-bed reactor. It is important to note that since a considerable fraction of the influent COD was soluble, the anaerobic digestion process was not as much limited by the hydrolysis step as other conventional anaerobic digestion processes (no significant limitation was observed in the reactor). Therefore, shorter time durations were enough for evaluating the behaviour of the control system either by simulation or in the pilotscale anaerobic fixed-bed reactor.

\section{Results and Discussion}

\subsection{Model-based design of the control system}

As commented above, the controller was designed, tuned and simulated using Matlab ${ }^{\circledR}$ Simulink ${ }^{\circledR}$ Fuzzy Logic Toolbox ${ }^{\mathrm{TM}}$ in order to assess its performance before being implemented in the AD system. Control system tuning was carried out by the classical trial-error approach until achieving adequate control behaviour 
(i.e. deviation below $5 \%$ of the established set point). The characteristics of the simulated wastewater were adjusted to the ones of the wastewater entering the pilot plant.

Figure 3 shows an example of the controller performance by simulation when operating at different set points for the gaseous outflow rate of methane. The control time (i.e. the time interval between two control actions) was set to 4 hours. As Figure 3a shows, the controller was sufficient to capture the dynamics of the process around different methane flow-rate set points. Nevertheless, the maximum effluent VFA concentration was reached from days 7 to 10 (see Figure 3b). Thus, as commented before, the effect of $e V F A$ cancelled the corresponding control action since it tended to increase eVFA. Only when the effluent VFA concentration was below its maximum threshold value it was possible to slightly increase the influent flow rate in order to compensate for the difference between methane flow rate and methane flow-rate set point (see day 9 in Figure 3).

Figure 4 shows an example of the controller performance by simulation when a continuous modification in the set point for the gaseous outflow rate of methane was applied over time. The control time was set also to 4 hours. Also in this case, the controller was sufficient to capture the dynamics of the process (see Figure 4a) around different methane flow-rate set points. Nevertheless, the maximum effluent VFA concentration was reached from days 6 to 11 (see Figure 4b). Thus, as commented before, the effect of $e V F A$ cancelled the corresponding control action since it tended to increase $e V F A$. In these operating conditions, the controller was only capable to increase the influent flow rate proportionally to the VFA consumption rate. As Figure 4b illustrates, the effluent VFA concentration remained nearby stable around the maximum established threshold value due to a slight, continuous VFA consumption. Only when the effluent VFA concentration distanced the maximum VFA threshold value (see days 11 to 18) it was possible to compensate the error in

the gaseous outflow rate of methane.

\subsection{Validation of the control system performance in the pilot plant}

Different disturbing tests were evaluated in the before-mentioned anaerobic fixed-bed reactor in order to assess the feasibility of the proposed controller for optimising biogas production in full-scale plants. 
Besides the controller performance simulation, different validation tests were conducted in the pilot plant. To this aim, different methane flow-rate set points and effluent VFA concentration reference values were selected according to the range of operation of the pilot plant. These values were selected on the basis of the process knowledge in order to optimise biogas production without risking process performance (e.g. high VFA concentrations usually mean acidification-related issues). Specifically, Figure 5 illustrates the behaviour of the fuzzy-logic control system when operating at a set point for the gaseous outflow rate of methane of $17 \mathrm{~L}_{\mathrm{CH}} 4 \mathrm{~h}^{-1}$. The reference value for the effluent VFA concentration was established at $350 \mathrm{mg}$ COD. $\mathrm{L}^{-1} \cdot \operatorname{In}$ this case, the control time (i.e. the time interval between two control actions) was set to 30 seconds, thus very low values were considered for the output linguistic labels. As Figure 5a shows, a fast response of the controller was obtained in order to compensate for the error in the methane flow rate, The results presented in Figure 5a reveal a proper behaviour of the fuzzy-logic controller since the methane flow rate reached a value of $17 \pm 1.8$ $\mathrm{L}_{\mathrm{CH} 4} \cdot \mathrm{h}^{-1}$, which corresponded to a deviation around $10 \%$ of the established set point. The average specific methane yield resulted in $0.28 \mathrm{LCH} \cdot \mathrm{kg}^{-1} \mathrm{COD}$ during this operating period.

With regard to effluent VFA concentration, Figure 5b illustrates that the reactor was operated at nearby stable conditions when the process was stabilised (see days from 1 to 2.5). Specifically, the average VFA content in the effluent resulted in approx. $450 \mathrm{mg}$ COD $\cdot \mathrm{L}^{-1}$ during the operating period. Bicarbonate concentration resulted in stable values around $70 \mathrm{mmol} \cdot \mathrm{L}^{-1}$. These stable bicarbonate values indicated adequate process stabilities not only due to the behaviour of the fuzzy-logic controller, but also because of the lower-layer $\mathrm{pH}$ control performance. As commented before, the $\mathrm{pH}$ controller added buffer solution $(\mathrm{NaOH})$ to the system when necessary, enhancing the fuzzy-logic control response towards perturbations (e.g. possible significant influent VFA dynamics). The ratio acetic acid/propionic acid resulted in values of around 1.22 during this operating period. Nevertheless, it is important to highlight that this value could be a non-adequate indicator of process stability due to the high influent VFA concentration. Indeed, the ratio acetic acid/propionic acid in the influent resulted in values of around 2.22 during this operating period. As regards the lower-layer $\mathrm{pH}$ controller, Figure 5b shows how the controller was capable to keep the $\mathrm{pH}$ around the established set point 
(7.2) by adding buffer solution when necessary. $\mathrm{pH}$ resulted in $7.27 \pm 0.14$ by adding $0.014 \mathrm{~L} \cdot \mathrm{h}^{-1}$ of $\mathrm{NaOH}$ in average.

Despite the considerable variation observed in the control action when operating at low control times (see Figure 5), the controlled variable remained at quite suitable values during the operating period. This fact highlights the wide range of application of fuzzy-logic-based controllers. In this respect, the controller resulted in adequate behaviours even when operating with non-optimised values for the control output parameters. Nevertheless, in order to optimise the control system performance, it is necessary to apply larger control times that allow compensating for the slow AD dynamics, thus reducing the range of variation of both controlled and manipulated variables.

Figure 6 illustrates the behaviour of the fuzzy-logic control system when operating with a set point for the gaseous outflow rate of methane of $15 \mathrm{~L}_{\mathrm{CH} 4} \cdot \mathrm{h}^{-1}$. The reference value for the effluent VFA concentration was $300 \mathrm{mg}$ COD $\cdot \mathrm{L}^{-1}$. In this case, the control time was set to 4 hours in order to compensate the slow $\mathrm{AD}$ dynamics. Two process disturbances were observed at days 0.6 and 3.6, respectively. The first disturbance (drop by $2.5 \mathrm{~L}_{\mathrm{CH} 4} \cdot \mathrm{h}^{-1}$ ) resulted from a sudden drop in the recycling flow rate due to partial clogging of the tubing (the recycling flow rate decreased from around 520 to $380 \mathrm{~L} \cdot \mathrm{h}^{-1}$ ); whilst the second one (increase by 3.5 $\mathrm{L}_{\mathrm{CH} 4} \cdot \mathrm{h}^{-1}$ ) resulted from purging the recirculation line and readjusting the recycling flow rate to $550 \mathrm{~L} \cdot \mathrm{h}^{-1}$. These changes in the sludge recycling flow rate modified the stripping rate of the produced gases from the liquid phase, thus affecting methane production. In this respect, the lower the recycling flow rate the lower the stripping rate of methane from the liquid phase and thus, the lower the gaseous outflow rate of methane. Nonetheless, Figure 6a shows how the control action was capable to compensate for both decreasing and increasing methane production disturbances, reaching the desired set point. Thus, the fuzzy-logic control action resulted in suitable performance under disturbances likely similar to the ones expected at full-scale plants (e.g. variations in the recycling flow rate).

Also in this case, the results presented in Figure 6a reveal a proper behaviour of the fuzzy-logic controller since the methane flow rate resulted in a value of $15 \pm 1 \mathrm{~L}_{\mathrm{CH} 4} \cdot \mathrm{h}^{-1}$, which corresponds to a deviation below 
$10 \%$ of the established set point. The average specific methane yield resulted in $0.31 \mathrm{LCH}^{*} \mathrm{~kg}^{-1} \mathrm{COD}$ during this operating period. The average effluent VFA concentration for this operating period remained nearby stable around approx. $330 \mathrm{mg}$ COD $\cdot \mathrm{L}^{-1}$ (see Figure 6b), highlighting an adequate performance of both control system and reactor (i.e., it was possible to control methane production whilst operating at adequate VFA concentrations). Bicarbonate concentration resulted in stable values around $80 \mathrm{mmol} \cdot \mathrm{L}^{-1}$. This concentration was higher than the one resulting when the set point for the gaseous outflow rate of methane was set to $17 \mathrm{~L}_{\mathrm{CH} 4} \cdot \mathrm{h}^{-1}$. It was mainly related to the lower VFA values reached when operating at a gaseous outflow rate of methane of around $15 \mathrm{~L}_{\mathrm{CH} 4} \cdot \mathrm{h}^{-1}$ (enhanced process stabilities were achieved). During this operating period, the ratio acetic acid/propionic acid resulted in values of around 1,19 (the ratio acetic acid/propionic acid in the influent was 1.54).

The lower-layer $\mathrm{pH}$ controller maintained the $\mathrm{pH}$ at values around $7.24 \pm 0.07$ by adding $0.007 \mathrm{~L} \cdot \mathrm{h}^{-1}$ of buffer solution in average. This buffer solution feeding rate was lower than the one resulting when the set point for the gaseous outflow rate of methane was set to $17 \mathrm{~L}_{\mathrm{CH} 4} \cdot \mathrm{h}^{-1}$. It is important to highlight that higher VFA values and VFA dynamics were reached when operating at $17 \mathrm{~L}_{\mathrm{CH}} 4^{\cdot} \mathrm{h}^{-1}$. In this respect, the lower the set point for the gaseous outflow rate of methane, the lower the organic loading rate (lower influent flow rates were applied by the controller). Hence, the lower-layer $\mathrm{pH}$ controller played an important role in terms of process stability (it allowed enhancing fuzzy-logic control performance) since the buffer solution feeding rate depended on the operating conditions.

\subsection{Performance of the control system under large process disturbances}

Figure 7 shows the behaviour of the fuzzy-logic controller for the case of a larger process disturbance and performing with non-optimised values for the control output parameters.

A problem in the feeding system (the buffer tank was empty from day 0.5 to 1.4 ) resulted in the introduction of air to the reactor with the influent flow during this operating period. Due to the introduction of air to the system, the methane concentration in the biogas decreased considerably. Thus, the controller maintained the influent flow rate at the maximum threshold value $\left(10 \mathrm{~L}^{-1} \mathrm{~h}^{-1}\right)$ in order to compensate the error in the methane flow rate. 
Nevertheless, a mixture of WWW and air was finally introduced to the system from day 0.5 to 1.4 , which could be identified by the measurement noise recorded in the influent flow rate (see Figure 7b). In this case, as can be seen in Figure 7b, the PID of the influent flow rate controller could not maintain the desired influent flow rate set point. The introduction of air to the system can also be identified in Figure 7c through the decrease in the reactor temperature during this period (e.g. the continuous introduction of fresh air acted as a refrigeration action on the system). Hence, the controller was not capable to push the controlled variable to values close to the established set point $\left(15 \mathrm{~L}_{\mathrm{CH}}{ }^{\cdot} \mathrm{h}^{-1}\right)$ despite setting the influent flow rate to its maximum value (i.e. $\left.10 \mathrm{~L} \cdot \mathrm{h}^{-1}\right)$, resulting in a decrease in the methane flow rate (see Figure 7a).

In addition, a decrease in $\mathrm{pH}$ was observed due to an additional failure in the lower-layer $\mathrm{pH}$ controller (no buffer solution was added to the system from day 0 to 1.4 , see Figure $7 \mathrm{c}$ ). It resulted in a consequent decrease in $\mathrm{pH}$ due to the introduction of fresh WWW until day 0.5 (pH reached values of about 5.7). Thus, as previously commented, the lower-layer $\mathrm{pH}$ controller also played an important role on process performance depending on operating conditions. Nevertheless, WWW was not fed to the system from day 0.5 to 1.4 since the buffer tank was empty, favouring a fast consumption of the available organic matter. Notice that the VFA concentration reached considerably low values around day 1.4 (see Figure 7d). Hence, if the fuzzy-logic controller would have commanded a decrease in the influent flow-rate, $\mathrm{pH}$ would have been partially compensated by adequate VFA consumption rates (see day 0.5 to 1.4 in Figure 7c).

Around day 1.4 the problems in the plant were solved and the influent flow rate was manually set to $5 \mathrm{~L} \cdot \mathrm{h}^{-1}$ before re-starting up the controller (at day 1.7). Different process disturbances were observed due to changes in the stripping rate of the produced gases from the liquid phase, as a result of changes in the sludge recycling flow rate (see days 2.2, 2.6, 2.7, 2.9, and 3.1) due to different partial clogging and purging the tubing. Specifically, the recycling flow varied as follows: $-65 \mathrm{~L} \cdot \mathrm{h}^{-1},-130 \mathrm{~L} \cdot \mathrm{h}^{-1},+90 \mathrm{~L} \cdot \mathrm{h}^{-1},-50 \mathrm{~L} \cdot \mathrm{h}^{-1}$, and $+105 \mathrm{~L} \cdot \mathrm{h}^{-1}$, respectively. Nonetheless, the controller was capable of successfully reaching the established set point from day 3 to the end of the operating period. 
The results of this study reveal that the proposed fuzzy-logic controller presents a high capability for compensating possible disturbances encountered in full-scale anaerobic fixed-bed reactors. Therefore, stable control responses were provided in order to adequately maintain the system around the established set point by applying softer changes on the manipulated variable. In this respect, the proposed controller would allow gathering the following safety knowledge-based requirements: i) maximum influent flow rate in order to avoid microorganisms washout and process acidification, which is time varying according to many operating factors such as wastewater composition or OLR; ii) maximum limit of VFA to avoid process acidification; and iii) maximum methane flow-rate set points that can be reached without inducing process acidification.

Nonetheless, for application of this fuzzy-logic control law at full-scale, adjustment of the main control parameters and control time interval would be needed to ensure adequate operation. In this respect, the following modifications might be considered, among others: 1) optimising the use of moving averages of the measured methane flow rate and VFA concentration to smooth the variations in the signals; 2) optimising the sampling time and the control time in order to avoid too slow control actions thus enhancing the optimisation of the AD system; and 3) optimising the centre, amplitude, and singleton values that define both fuzzification and defuzzification in order to enhance the control response towards perturbations.

\section{Conclusions}

A fuzzy-logic-based controller has been developed, tuned and validated in order to control the methane production in continuous fixed-bed anaerobic reactors. The main characteristics of the control approach are the following: controlling methane production whilst operating at adequate VFA concentrations; achieving adequate process stabilities within the typical perturbations encountered in full-scale anaerobic fixed-bed reactors; using the on-line equipment available in the plant (flow-rate transmitters, gas flow transmitter, on line $\mathrm{CH}_{4} / \mathrm{CO}_{2}$ sensor and on-line titrimetric sensor); and being easy-working and adaptable to the new operational requirements. The performance of the controller was evaluated under specific conditions that are similar to the ones expected at full-scale plants. The controller was sufficient to capture the dynamics of the process around the corresponding set point. 


\section{Acknowledgements}

This research work has been supported by the EU (FP7-SME-2008-1 call, project ADD CONTROL 232302) and the Spanish Research Foundation (MICINN FPI grant BES-2009-023712), which are gratefully acknowledged.

\section{References}

[1] Guo XM., Trably E, Latrille E, Carrère H, Steyer J-P. Hydrogen production from agricultural waste by dark fermentation: A review. Int. J. Hydrog. Energy 2010;35:10660-10673.

[2] Aceves-Lara CA, Latrille E, Steyer J-P. Optimal control of hydrogen production in a continuous anaerobic fermentation bioreactor. Int. J. Hydrog. Energy 2010;35:10710-10718.

[3] Ward AJ, Hobbs PJ, Holliman PJ, Jones DL. Optimization of the anaerobic digestion of agricultural resources. Bioresour. Technol. 2008;99:7928-7940.

[4] Couras CS, Louros VL, Gameiro T, Alves N, Silva A, Capela MI, Arroja LM, Nadais H. Anaerobic degradation of dairy wastewater in intermittent UASB reactors: influence of effluent recirculation. Environ. Technol. 2015;17:2227-2238.

[5] Wahab MA, Habouzi F, Bernet N, Jedidi N. Escudié R. Evaluation of a hybrid anaerobic biofilm reactor treating winery effluents and using grape stalks as biofilm carrier. Environ. Technol. 2016;37:1676-1682. [6] Zhaoa B, Li J, Buelna G, Dubé R, Bihan Y. A combined upflow anaerobic sludge bed and trickling biofilter process for the treatment of swine wastewater. Environ. Technol. 2016;10:1265-1275.

[7] Boe K, Batstone DJ, Steyer J-P, Angelidaki I. State indicators for monitoring the anaerobic digestion process. Water Res. 2010;44:5973-5980.

[8] JimenezJ, Latrille E, Harmand J, Robles A, Ferrer J, Gaida D, Wolf C, Mairet F, Bernard O, AlcarazGonzalez V, Mendez-Acosta H, Zitomer D, Totzke D, Spanjers H, Jacobi F, Guwy G, Dinsdale R, Premier G, Mazhegrane S, Ruiz-Filippi G, Seco A, Ribeiro T, Pauss A, Steyer J-P. Instrumentation and control of anaerobic digestion processes: a review and some research challenges. Rev Environ Sci Biotechnol 2015; 14:615-648.

[9] Zadeh LA. Fuzzy sets. Information and Control 1965;8:338-353. 
[10] Estaben M, Polit M, Steyer J-P. Fuzzy control for an anaerobic digester. Control Eng. Practice 1997;5:1303-1310.

[11] Genovesi A, Harmand J, Steyer J-P. A fuzzy logic based diagnosis system for the on-line supervision of an anaerobic digestor pilot-plant. Biochem. Eng. J. 1999;3:171-183.

[12] Puñal A, Palazzotto L, Bouvier JC, Conte T, Steyer J-P. Automatic control of volatile fatty acids in anaerobic digestion using a fuzzy logic based approach. Water Sci. Technol. 2003;48:103-10.

[13] Garcia C, Molina F, Roca E, Lema JM. Fuzzy-Based Control of an Anaerobic Reactor Treating Wastewaters Containing Ethanol and Carbohydrates. Ind Eng Chem Res 2007;46:6707-6715.

[14] Martinez-Sibaja A, Posada-Gomez R, Alvarado-Lassman A, Sebastia-Cortes A. Cascade Fuzzy Logic Controller for an Anaerobic Digester. In Electronics, Robotics and Automotive Mechanics Conference (CERMA 2007) 2007;1:395-399.

[15] Scherer P, Lehmann K, Schmidt O, Demirel B. Application of a fuzzy logic control system for continuous anaerobic digestion of low buffered, acidic energy crops as mono-substrate. Biotechnol Bioeng 2009;102:736-48.

[16] Carlos-Hernandez S, Sanchez E, Beteau J. Fuzzy Control Strategy for an Anaerobic Wastewater Treatment Process, Chem Biochem Eng Q 2010;24:235-245.

[17] Gurubel KJ, Sanchez EN, Carlos-Hernandez S, Ornelas-Tellez F. PSO hybrid intelligent inverse optimal control for an anaerobic process. In 2013 IEEE Congress on Evolutionary Computation 2013;1:876-883.

[18] Verbruggen HB, Bruijn PM. Fuzzy control and conventional control: What is (and can be) the real contribution of Füzy Systems?. Fuzzy Sets Syst. 1997;90:151-160.

[19] Olsson G, Nielsen MK, Yuan Z, Lynggaard-Jensen A, Steyer JP. Instrumentation, Control and Automation in Wastewater Systems. IWA; 2005.

[20] Standard methods for the Examination of Water and Wastewater, 21st ed. American Public Health Association/American Water Works Association/Water Environmental Federation. Washington DC, USA, 2005.

[21] Larsen PM. Industrial application of fuzzy logic control. Int. J. Man-Mach. Stud. 1980;12:3-10.

[22] Mendel JM. Fuzzy logic systems for engineering: a tutorial. Proc. IEEE 1995;83:345-375. 
[23] Barat R, Serralta J, Ruano MV, Jiménez E, Ribes J, Seco A, Ferrer J. Biological Nutrient Removal Model No 2 (BNRM2): A general model for Wastewater Treatment Plants. Water Sci. Technol. 2013;67:1481-1489.

\section{Table and Figure captions}

Table 1. Fuzzy-logic control action: grade of membership to the output linguistic labels. ${ }^{*} e q_{C H_{4}}<0 ;{ }^{* *} e q_{C H_{4}}>0$. 
Figure 1. Flow diagram of the plant, including instrumentation. (Nomenclature: FIT: Flow-Indicator-Transmitter; PIT: Pressure-Indicator-Transmitter; pH: pH-Transmitter; CT: Conductivity-Transmitter; T: Temperature sensor; PLC: Programmable Logic Controller).

Figure 2. Block diagram of the proposed fuzzy-logic controller.

Figure 3. Fuzzy-logic controller performance by simulation when conducting different step changes in the set point for the gaseous outflow rate of methane. Evolution of: (a) methane flow rate, methane flow-rate set point and influent flow rate; and (b) effluent VFA concentration.

Figure 4. Fuzzy-logic controller performance by simulation when conducting a continuous modification in the set point for the gaseous outflow rate of methane. Evolution of: (a) methane flow rate; methane flow-rate set point and influent flow rate; and (b) effluent VFA concentration.

Figure 5. Performance of the fuzzy-logic controller in the pilot plant when operating at: control time of 30 seconds, reference VFA concentration of $350 \mathrm{mg} \mathrm{COD} \cdot \mathrm{L}^{-1}$, and set point for the gaseous outflow rate of methane of $17 \mathrm{~L}_{\mathrm{CH} 4} \cdot \mathrm{h}^{-1}$. Evolution of: (a) methane flow rate and influent flow rate; and (b) VFA concentration, influent flow rate, $\mathrm{pH}$ and gross $\mathrm{NaOH}$ flow rate for $\mathrm{pH}$ control.

Figure 6. Performance of the fuzzy-logic controller in the pilot plant when operating at: control time of 4 hours, reference VFA concentration of $300 \mathrm{mg} \mathrm{COD} \cdot \mathrm{L}^{-1}$, and set point for the gaseous outflow rate of methane of $15 \mathrm{LCH}_{\mathrm{CH}} \cdot \mathrm{h}^{-1}$. Evolution of: (a) methane flow rate and influent flow rate; and (b) VFA concentration, influent flow rate, $\mathrm{pH}$ and gross $\mathrm{NaOH}$ flow rate for $\mathrm{pH}$ control.

Figure 7. Performance of the fuzzy-logic controller for a large process disturbance due to different operating problems when operating at control time of 30 seconds and set point for the gaseous outflow rate of methane of $15 \mathrm{~L}_{\mathrm{CH} 4} \mathrm{~h}^{-1}$. Evolution of (a) methane flow rate and methane flow-rate set point; (b) influent flow rate and influent flow-rate set point; (c) temperature, $\mathrm{pH}$ and gross $\mathrm{NaOH}$ flow rate for $\mathrm{pH}$ control; and (d) influent flow-rate set point and VFA concentration

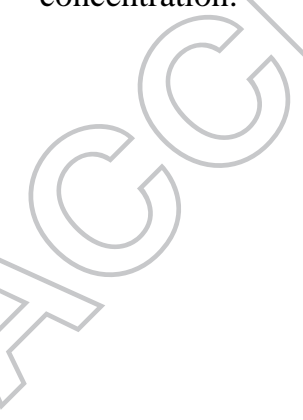

Table 1. Fuzzy-logic control action: grade of membership to the output linguistic labels. ${ }^{*} e q_{C H_{4}}<0 ;{ }^{* *} e q_{C H_{4}}>0$. 


\begin{tabular}{ll}
1 & $\mu\left(\Delta q_{I N \_S P}\right)_{\mathrm{HP}}=\mu\left(e q_{C H 4}\right)_{\mathrm{N}} \cdot \mu\left(\Delta e q_{C H 4}\right)_{\mathrm{Z}} \cdot\left(1-\mu(e V F A)_{\mathrm{P}}\right)$ \\
2 & $\mu\left(\Delta q_{I N \_S P}\right)_{\mathrm{HP}}=\mu\left(e q_{C H 4}\right)_{\mathrm{N}} \cdot \mu\left(\Delta e q_{C H 4}\right)_{\mathrm{P}} \cdot\left(1-\mu(e V F A)_{\mathrm{P}}\right)$ \\
3 & $\mu\left(\Delta q_{I N \_S P}\right)_{\mathrm{HN}}=\mu\left(e q_{C H 4}\right)_{\mathrm{P}} \cdot \mu\left(\Delta e q_{C H 4}\right)_{\mathrm{Z}} \cdot\left(1-\mu(e V F A)_{\mathrm{N}}\right)$ \\
4 & $\mu\left(\Delta q_{I N \_S P}\right)_{\mathrm{HN}}=\mu\left(e q_{C H 4}\right)_{\mathrm{P}} \cdot \mu\left(\Delta e q_{C H 4}\right)_{\mathrm{P}} \cdot\left(1-\mu(e V F A)_{\mathrm{N}}\right)$ \\
$5 \mathrm{a}^{*}$ & $\mu\left(\Delta q_{I N_{-} S P}\right)_{\mathrm{LP}}=\mu\left(e q_{C H 4}\right)_{\mathrm{Z}} \cdot \mu\left(\Delta e q_{C H 4}\right)_{\mathrm{N}} \cdot\left(1-\mu(e V F A)_{\mathrm{P}}\right)$ \\
$5 \mathrm{~b}^{* *}$ & $\mu\left(\Delta q_{I N \_S P}\right)_{\mathrm{LN}}=\mu\left(e q_{C H 4}\right)_{\mathrm{Z}} \cdot \mu\left(\Delta e q_{C H 4}\right)_{\mathrm{N}} \cdot\left(1-\mu(e V F A)_{\mathrm{N}}\right)$ \\
$6 \mathrm{a}^{*}$ & $\mu\left(\Delta q_{I N \_S P}\right)_{\mathrm{LP}}=\mu\left(e q_{C H 4}\right)_{\mathrm{Z}} \cdot \mu\left(\Delta e q_{C H 4}\right)_{\mathrm{P}} \cdot\left(1-\mu(e V F A)_{\mathrm{P}}\right)$ \\
$6 \mathrm{~b}^{* *}$ & $\mu\left(\Delta q_{I N \_S P}\right)_{\mathrm{LN}}=\mu\left(e q_{C H 4}\right)_{\mathrm{Z}} \cdot \mu\left(\Delta e q_{C H 4}\right)_{\mathrm{P}} \cdot\left(1-\mu(e V F A)_{\mathrm{N}}\right)$ \\
\hline
\end{tabular}




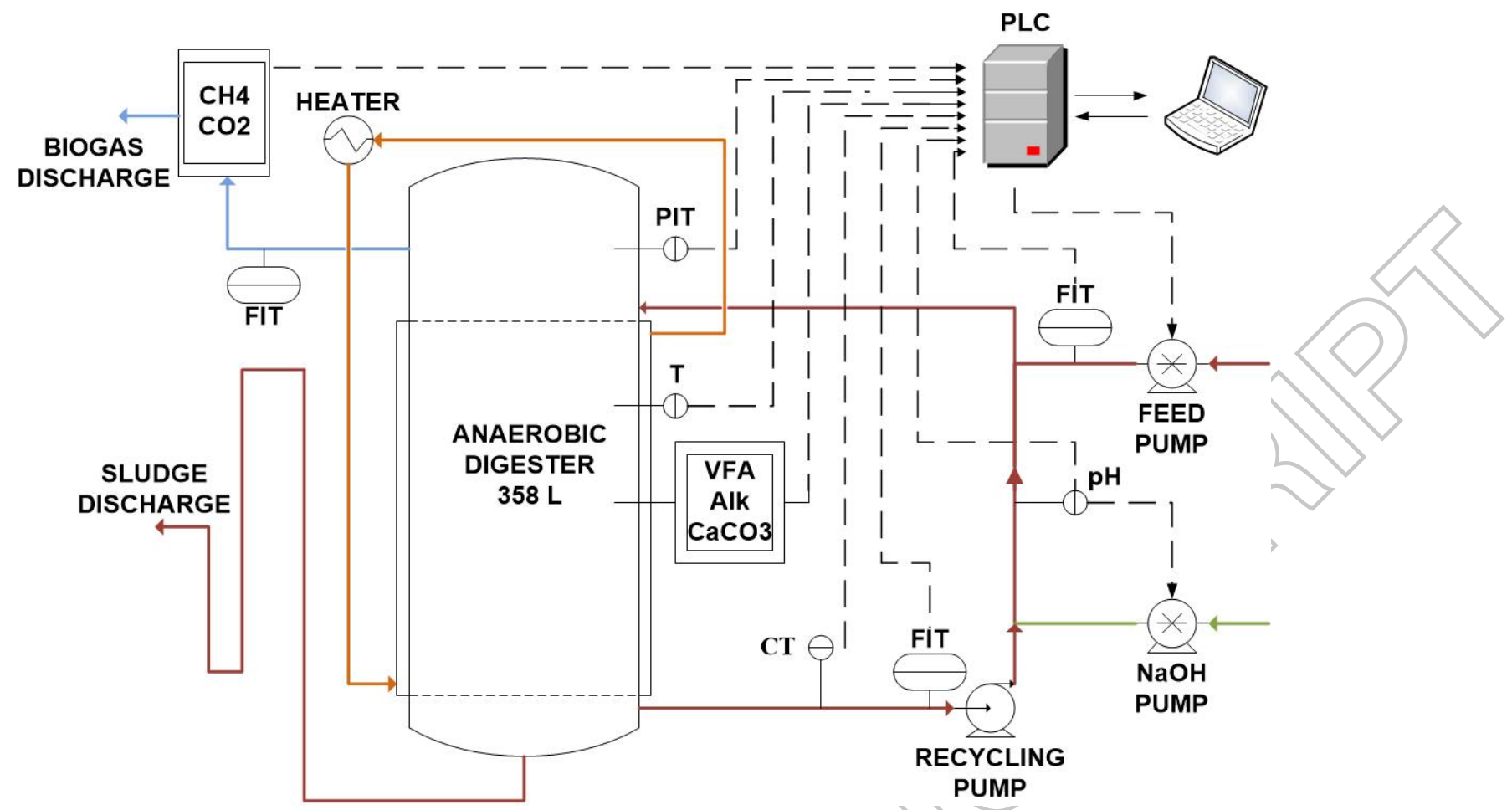

Figure 1. Flow diagram of the plant, including instrumentation. (Nomenclature: FIT: Flow-Indicator-Transmitter; PIT:

Pressure-Indicator-Transmitter; $\mathbf{p H}$ : pH-Transmitter; CT: Conductivity-Transmitter; $\mathbf{T}$ : Temperature sensor; PLC:

Programmable Logic Controller). 


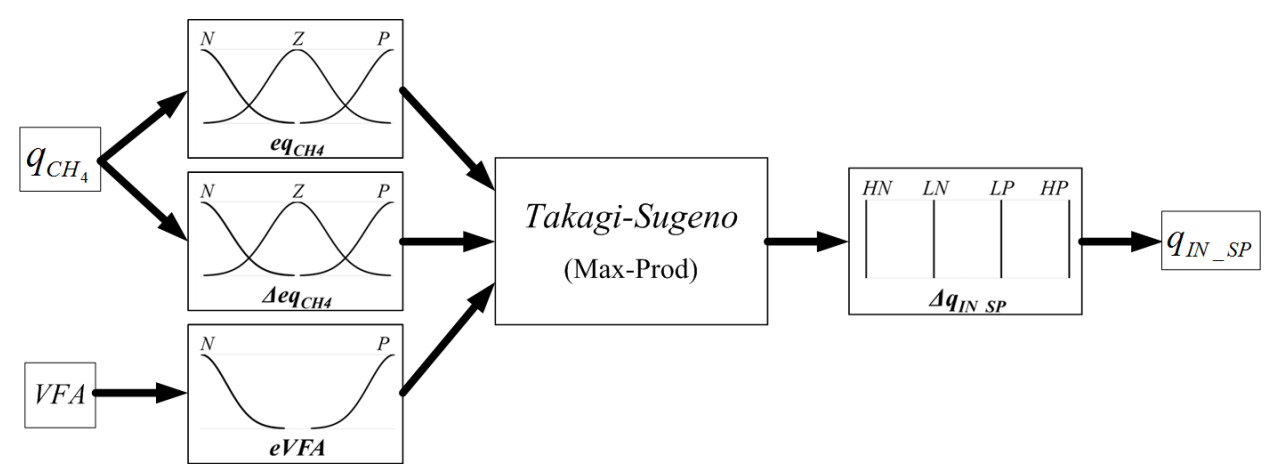

Figure 2. Block diagram of the proposed fuzzy-logic controller. 


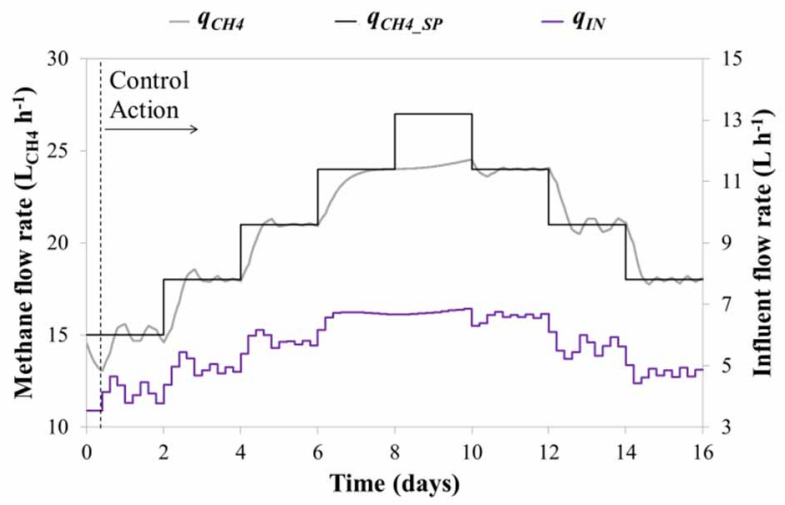

(a)

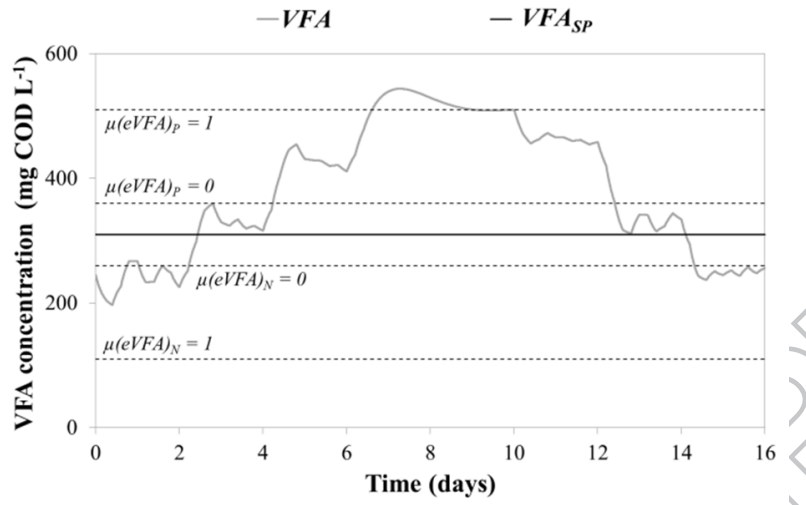

(b)

Figure 3. Fuzzy-logic controller performance by simulation when conducting different step changes in the set point for the gaseous outflow rate of methane. Evolution of: (a) methane flow rate, methane flow-rate set point and influent flow rate; and (b) effluent VFA concentration. 


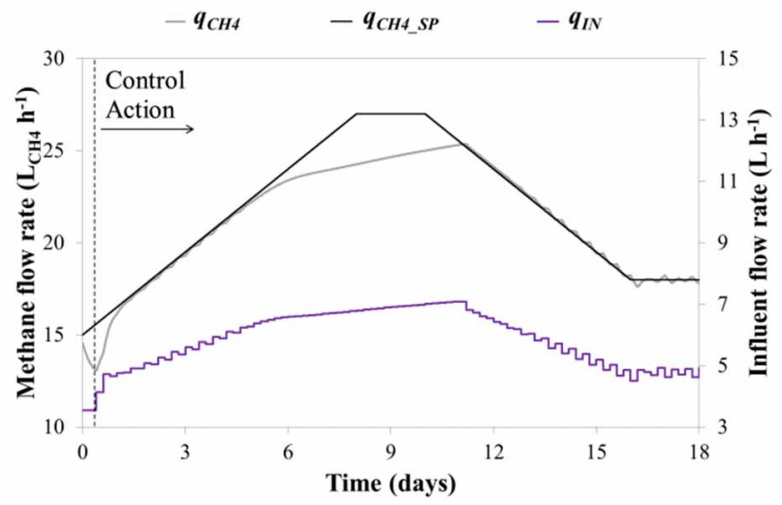

(a)

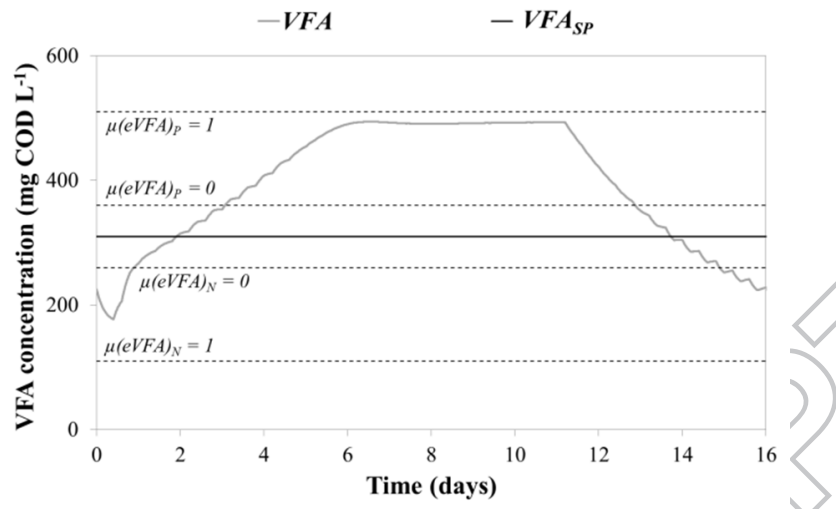

(b)

Figure 4. Fuzzy-logic controller performance by simulation when conducting a continuous modification in the set point for the gaseous outflow rate of methane. Evolution of: (a) methane flow rate; methane flow-rate set point and influent flow rate; and (b) effluent VFA concentration. 


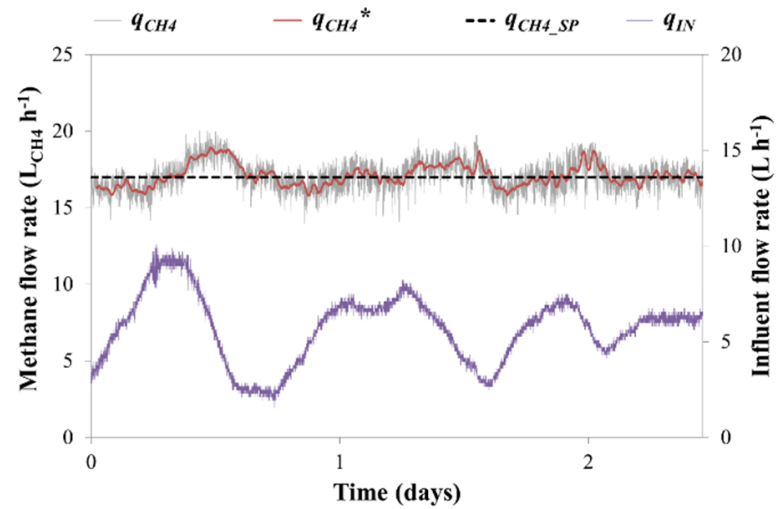

(a)

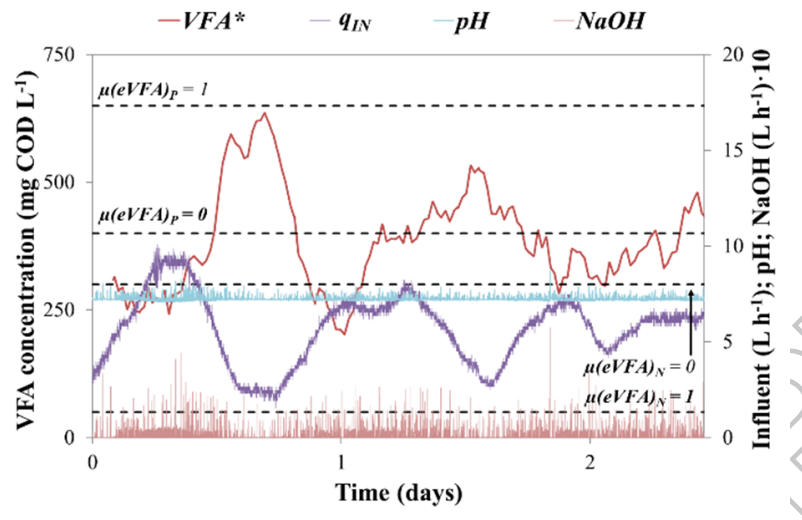

(b)

Figure 5. Performance of the fuzzy-logic controller in the pilot plant when operating at: control time of 30 seconds, reference VFA concentration of $350 \mathrm{mg} \mathrm{COD} \cdot \mathrm{L}^{-1}$, and set point for the gaseous outflow rate of methane of $17 \mathrm{~L}_{\mathrm{CH} 4} \cdot \mathrm{h}^{-1}$. Evolution of: (a) methane flow rate and influent flow rate; and (b) VFA concentration, influent flow rate, $\mathrm{pH}$ and gross $\mathrm{NaOH}$ flow rate for $\mathrm{pH}$ control. 


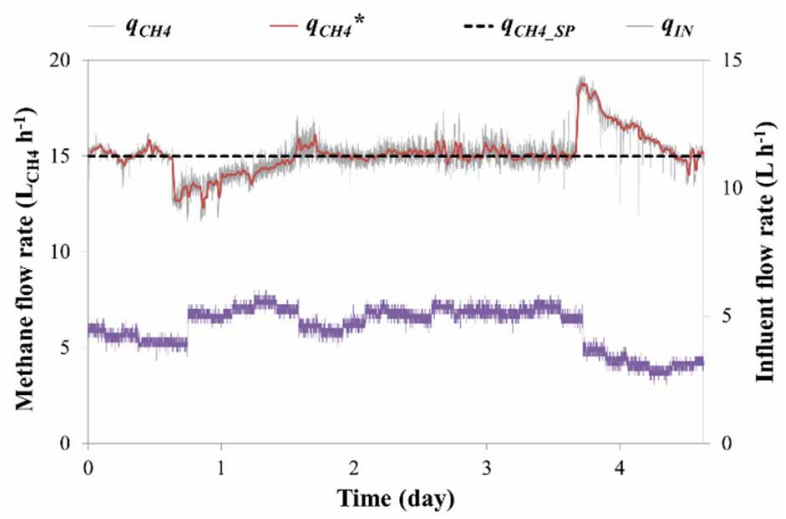

(a)

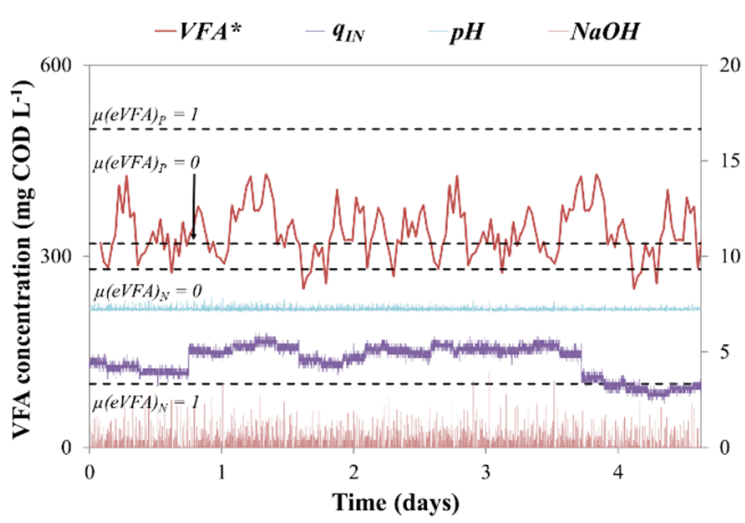

(b)

Figure 6. Performance of the fuzzy-logic controller in the pilot plant when operating at: control time of 4 hours, reference VFA concentration of $300 \mathrm{mg} \mathrm{COD} \cdot \mathrm{L}^{-1}$, and set point for the gaseous outflow rate of methane of $15 \mathrm{LCH}_{\mathrm{CH}} \cdot \mathrm{h}^{-1}$. Evolution of: (a) methane flow rate and influent flow rate; and (b) VFA concentration, influent flow rate, $\mathrm{pH}$ and gross $\mathrm{NaOH}$ flow rate for $\mathrm{pH}$ control. 


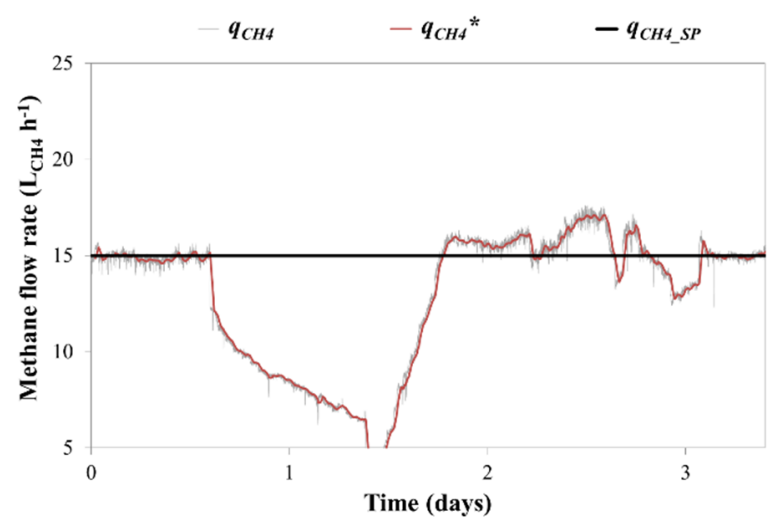

(a)

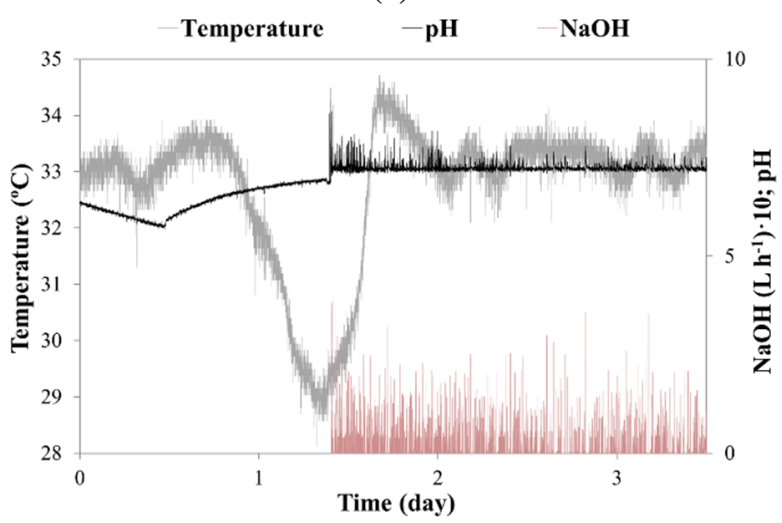

(c)

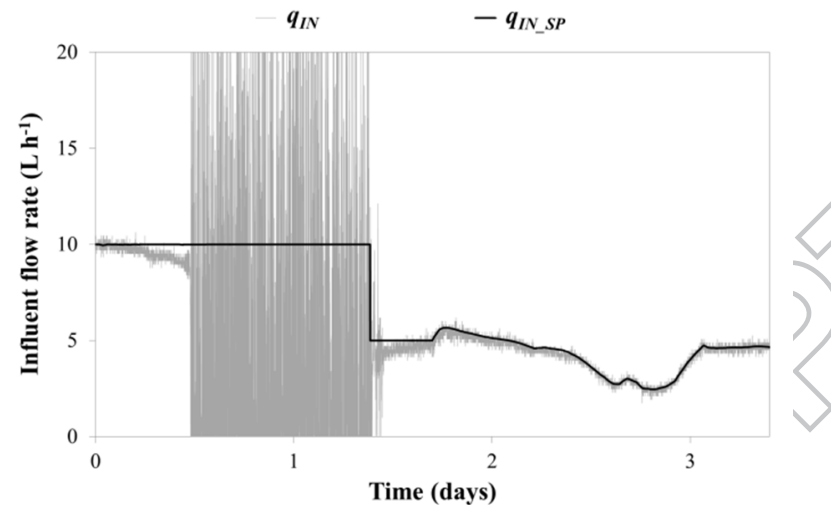

(b)

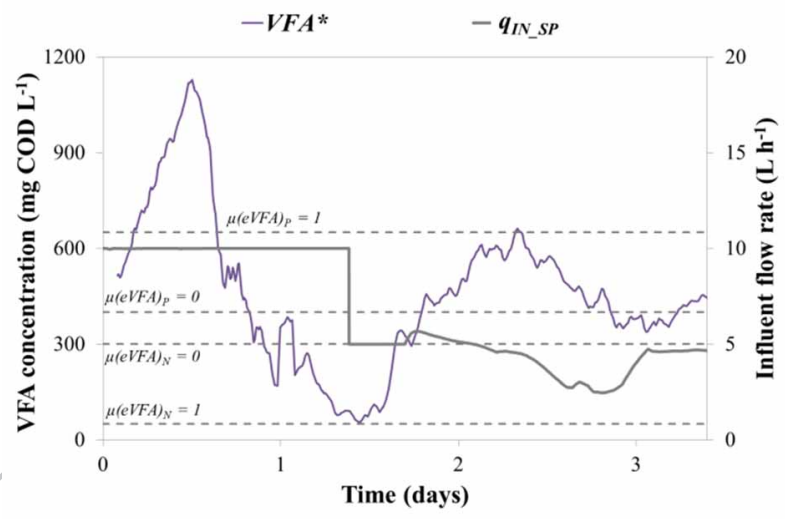

(d)

Figure 7. Performance of the fuzzy-logic controller for a large process disturbance due to different operating problems when operating at control time of 30 seconds and set point for the gaseous outflow rate of methane of $15 \mathrm{~L}_{\mathrm{CH} 4} \mathrm{~h}^{-1}$. Evolution of (a) methane flow rate and methane flow-rate set point; (b) influent flow rate and influent flow-rate set point; (c) temperature, $\mathrm{pH}$ and gross $\mathrm{NaOH}$ flow rate for $\mathrm{pH}$ control; and (d) influent flow-rate set point and VFA concentration. 